\title{
DISCRIMINAÇÃO E PRECONCEITO LINGUÍSTICO: QUESTÕES PARA PROMOÇÃO DA SAÚDE?
}

\section{ARTIGO ORIGINAL}

FALCÃO, Ana Regina Graner ${ }^{1}$

SOUZA, Luiz Augusto de Paula ${ }^{2}$

COSTA, Rogério da ${ }^{3}$

FALCÃO, Ana Regina Graner. SOUZA, Luiz Augusto de Paula. COSTA, Rogério da. Discriminação e preconceito linguístico: questões para promoção da saúde? Revista Científica Multidisciplinar Núcleo do Conhecimento. Ano 05, Ed. 03, Vol. 02, pp. 17-31. Fevereiro de 2020. ISSN: 2448-0959, Link de acesso: https://www.nucleodoconhecimento.com.br/saude/discriminacao-e-

\section{preconceito}

\section{RESUMO}

As variedades linguísticas socialmente desprestigiadas em relação à chamada norma culta, podem configurar processos de discriminação e exclusão social em ambientes sociais diversos. A desqualificação social derivada da discriminação e do preconceito linguístico, quando naturalizada, pode sugerir que falantes discriminados tem

\footnotetext{
${ }_{1}$ Professora assistente do curso de Fonoaudiologia, do Departamento de Ciências da Vida da Universidade do Estado da Bahia - UNEB, Doutoranda em Fonoaudiologia pela PUC-SP.

2 Doutor em psicologia clínica e professor titular da Faculdade de Ciências Humanas e da Saúde da PUC-SP.

${ }^{3}$ Doutor em filosofia pela Université Paris IV - Sorbonne, professor do Departamento de Ciências da Linguagem e Filosofia da PUCSP e do Programa de Pós-Graduação em Comunicação e Semiótica da PUC-SP.
} 
dificuldades individuais de aprendizagem ou de saúde, por suposta alteração cognitiva, articulatória ou de comunicação. Este estudo partiu de situação concreta, vivenciada em clínica-escola universitária: procura de jovens e adultos com queixas relacionadas aos modos de falar, sob a premissa de que a discriminação desses modos poderia indicar agravo de saúde. O objetivo da pesquisa foi investigar e caracterizar essa demanda através de estudo de caso, com estratégia metodológica de Grupo de Discussão. Os resultados da pesquisa sugerem a existência de "patologização" das variações dos modos de falar, que levam a efeitos sociais e subjetivos com potencial para prejudicar a saúde, além das oportunidades de inserção social e econômica, e do exercício da cidadania. Situação que leva à indagação: não seria esta uma situação de vulnerabilidade a ser considerada em ações de promoção da saúde?

Palavras-chave: Promoção da Saúde, preconceito linguístico, vulnerabilidade em saúde.

\section{INTRODUÇÃO}

A promoção da saúde, a partir de meados da década de 1970, deixa de ser pensada apenas como um componente da prevenção primária em saúde, tal como a definia a História Natural da Doença. A percepção mais aguda de que a saúde e o processo de saúde/doença são produções sociais multifacetadas é uma das dimensões responsáveis pela mudança, ela aponta para o fato de que saúde e doença são engendradas e moduladas no tempo pelas relações, contextos e condições subjetivas, familiares, ambientais, econômicas, políticas e culturais das pessoas, famílias, grupos e sociedades.

Segundo Ayres ${ }^{1}$, esse processo é nomeado "Nova Promoção da Saúde" e significa uma guinada nos modos de avaliar, planejar e gerir os serviços e os cuidados à saúde. Embora o engendramento da Nova Promoção da Saúde comece nos anos de 1970, o impulso decisivo para sua efetivação 
veio das Conferências Internacionais sobre "Promoção da Saúde" Ottawa, 1986; Adelaide, 1988; Sundsvall, 1991; Jacarta, 1997; México 2000; Bangkok 2006. Ao longo dessas conferências, que reuniram técnicos, gestores, políticos e ativistas, foram sendo consolidados os conceitos e estratégias para uma efetiva mudança de paradigma na orientação das práticas de saúde e melhoria das condições de saúde das populações em todo o mundo, especialmente entre as nações e grupamentos sociais mais pobres. Em cada uma destas conferências o debate de ideias e experiências dos diversos países participantes, seus sucessos e seus fracassos, seus avanços e suas dificuldades foram, pouco a pouco, constituindo um corpo de princípios e métodos que tem conferido novo sentido às práticas de saúde, especialmente no campo da "prevenção". ${ }^{1}$ (p. 18 - grifos do autor)

Sem a pretensão de detalhar as bases da Nova Promoção da Saúde, é possível indicar, brevemente, o que elas sustentam atualmente. Ainda segundo Ayres (op. cit.), os princípios da Nova Promoção da Saúde podem ser assim sintetizados:

- concepção de saúde como bem-estar físico, mental, social e espiritual, não de grupos de riscos, mas da população como um todo, em suas experiências cotidianas concretas;

- articulação de diferentes setores de atividade social (intersetorialidade). Além da saúde, educação, bem-estar social, trabalho, moradia, alimentação, lazer, transporte, planejamento urbano, setores jurídico, tributareis e fiscal, entre outros;

- "empoderamento" dos indivíduos para transformar situações sociais que constrangem ou ameaçam a saúde, com a garantia de direitos de cidadania, apoio jurídico, suporte social

- participação social, para que a definição de prioridades e de meios para alcançá-las resultem de construção social coletiva;

- equidade, no sentido de que a efetividade do direito à saúde depende de estratégias que contemplem as especificidades dos diferentes grupos sociais, 
ou seja, sem tratar a desigualdade como tal não é possível construir acesso universal à saúde;

- ações multi-estratégicas, com propostas interdisciplinares e intersetoriais, fazendo dialogar saberes diferentes para equacionar os modos de intervir nos processos de saúde-doença;

- sustentabilidade, fazendo com que as políticas de promoção de saúde respondam ao princípio do desenvolvimento econômico sustentável, bem como garantam continuidade e efetividade de suas ações,

Tal processo sugere, então, a intensificação do diálogo entre saberes científicos e técnicos com os valores dos indivíduos e comunidades, de maneira que se aumente, progressivamente, o conhecimento e a capacidade de intervenção sobre os determinantes dos processos de saúde-doença-cuidado e, por consequência, sobre a vida e a saúde.

Sob a abertura produzida pela nova visão de promoção da saúde desenvolve-se o conceito de vulnerabilidade em saúde, que não exclui as dimensões relacionadas à noção de risco em saúde, mas a redimensiona, como condição de produção social e não apenas como característica biológica e/ou comportamental de indivíduos e grupos considerados isoladamente. Nessa medida, os riscos estão implicados em produções sociais que vulneram a saúde de indivíduos e grupos sociais.

O enfrentamento de vulnerabilidades em saúde passa, então e entre outros fatores, por avaliar situações sociais e institucionais que atuem como fatores que reduzam, reproduzam ou aumentem as condições de risco de indivíduos e grupos em seus contextos concretos de vida. O quanto nossos serviços de saúde, propiciam que estes contextos desfavoráveis sejam percebidos e modificados por indivíduos, comunidades e grupos sociais ${ }^{1}$ ? Essa é uma das questões que precisam ser respondidas para orientar a definição e o planejamento de ações de promoção da saúde.

É no plano da vulnerabilidade social em saúde que a discussão de questões relativas ao preconceito linguístico e aos seus efeitos na saúde e na qualidade de vida parecem se situar. Mariani lembra que se pode definir preconceito como um "pré-julgamento, 
em geral, ingênuo, ligado ao senso comum, à crenças que dão suporte a certezas injustificadas". Por sua vez, Mezan³ acrescenta que

preconceito é o conjunto de crenças, atitudes e comportamentos que consiste em atribuir a qualquer membro de determinado grupo humano uma característica negativa, pelo simples fato de pertencer àquele grupo: a característica em questão é vista como essencial, definidora da natureza do grupo e, portanto, adere indelevelmente a todos os indivíduos que o compõem.

Conforme Crochik ${ }^{4}$, o preconceito é comum nas sociedades que se sustentam na injustiça e na desigualdade, e seu combate é fundamental, principalmente para conter a violência. O preconceito não é uma questão individual, em que pese sua manifestação via indivíduos. Segundo o autor, é preciso buscar na sociedade o que leva o indivíduo a ser ou não preconceituoso. Na esteira do preconceito emerge a discriminação, e sua visibilidade expressa-se fortemente, em nossa sociedade, por exemplo, na violência (econômica, política, simbólica e/ou física) contra negros, indígenas, pessoas com deficiência, LGBTQs, mulheres, adversários políticos e religiosos. As variações socioculturais na fala também podem ser objeto ou alvo de preconceito, tanto linguístico quanto de modos de expressão de outros preconceitos: étnicos, de classe, de gênero..., funcionando como variável da exclusão social e de outras formas de violência.

Em nosso estudo, um bom número de falantes de variações linguísticas, supondo algum distúrbio de fala, procuraram o serviço de saúde com a queixa de sofrer discriminação por preconceito linguístico, por preconceitos étnicos e/ou de classe, externalizados pela desqualificação aos seus modos de falar.

Esses falantes experimentam desde sensação reiterada de inferioridade social, retraimento social em certos ambientes (escolar, profissional, etc.), até rebaixamento da autoestima; dimensões que podem levar, segundo os relatos, à crises de ansiedade ou a episódios depressivos. 
Nesse ponto, é possível indagar se as políticas de promoção da saúde (da formação dos profissionais às práticas dos serviços) promovem ações sistemáticas que, de fato, resultam em fortalecimento dos sujeitos e das coletividades para afirmarem as diferenças e a diversidade social em seus modos de comunicação, como formas de produzir saúde e de enfrentar vulnerabilidades em saúde.

Deve-se lembrar que nossa sociedade é profundamente desigual e hierarquizada, consequentemente, os valores culturais e simbólicos que nela circulam também estão hierarquizados e, com frequência, não de modo inclusivo e democrático. Entre os valores simbólicos estão aspectos e dimensões da língua, produzidos ou mantidos por ela. Por mais que linguistas problematizem a norma prestigiada, por nem de longe corresponder inteiramente às realidades de uso efetivo da língua, eles não desprezam o fato de que, na condição de bem simbólico, existe demanda social por uma língua unificada e supostamente correta, identificada como instrumento necessário, embora não suficiente, para o acesso ao prestígio e aos bens sociais ${ }^{5}$.

É importante salientar que variações de fala nem sempre correspondem a distúrbios de comunicação, e que os chamados "erros" na aquisição da fala, em geral, são processos constitutivos da apropriação das convenções linguísticas ${ }^{6}$.

O preconceito linguístico é embasado na crença de que existe uma única língua digna e que esta seria a língua ensinada nas escolas, explicada nas gramáticas e catalogada nos dicionários ${ }^{5}$. Quando os falantes desviam desse padrão, a eles são atribuídos "erros", quando o necessário seria estudar as diferenças, compreendendo-as adequadamente, o que poderia, inclusive, redefinir padrões de ensino e de conduta, principalmente, no âmbito socioeducacional ${ }^{7}$.

Os erros tomados como dificuldades individuais do aprendiz, não apenas ajudam a reproduzir o imaginário que "patologiza" certos usos da língua falada, mas podem significar manifestações coletivas decorrentes de fatos inerentes à própria história da língua. É preciso que haja consciência das variedades da língua portuguesa, mesmo que, na escola, a língua ensinada seja o português padrão. A escola deveria levar em consideração as diferenças linguísticas presentes nas falas e nas produções escritas 
dos estudantes, percebendo que nem sempre essas diferenças são erros ou indícios de problemas de aprendizagem ou de saúde ${ }^{8}$.

Nesse sentido, há estudos que oferecem outras formas de abordar os "erros", apontando, por exemplo, fenômenos que ocorreram no processo de mudanças históricas da língua portuguesa: o caso da rotacização do /// em encontros consonantais, como em "probrema" é ilustrativo. Na passagem do latim para o português, algumas palavras sofreram o rotacismo e algumas classes sociais não acompanharam esse processo, cristalizando a forma arcaica, como as usadas por Camões $^{9,10}$.

O mesmo tipo de raciocínio explica "erros" do tipo "abêia", no qual há uma transformação do /K / em /i/, por questões e influências de ordem histórica. Justifica, também, a redução dos ditongos, tipo "sodade" e "bejo", com explicações referentes à assimilação, o mesmo fenômeno que acontece com a denasalização das vogais postônicas (ex.: homem - "home") ${ }^{10}$.

A partir de explicações processuais e contextualizadas, social e historicamente, surge a necessidade de se questionar não apenas as concepções de erro, mas também as formas com as quais eles são avaliados e tratados, quer seja clinicamente (pela foniatria, otorrinolaringologia, fonoaudiologia e psicologia, principalmente), quer seja no ambiente escolar ${ }^{11}$. Não existe nenhuma justificativa ética, política ou científica para continuar condenando como "erros ou indício de agravo à saúde usos linguísticos que estão firmados no português brasileiro há muito tempo, inclusive na fala e na escrita dos cidadãos privilegiados. É preciso reconhecer a variedade de formas de uso da língua falada e permitir o seu convívio tranquilo com as formas consagradas pela gramática normativa ${ }^{12}$.

A língua nacional, ensinada na escola, preconizada como norma, pouco ou quase nada tem a ver com o modo como os brasileiros e brasileiras falam ${ }^{8}$. Eles, em sua maioria, não se identificam inteiramente com o que é chamado de língua nacional, que é uma representação abstrata que projeta um imaginário de unidade². 
Do ponto de vista da área da saúde, uma maneira de intervir nesse cenário problemático seria, por exemplo, fomentar inciativas para equacionar questões de comunicação pessoal e interpessoal por meio da Educação Permanente em Saúde, uma vez que é uma estratégia vigente para a recomposição de práticas de formação, cuidado, participação social e reflexão sobre as políticas de saúde. Também seria necessário o estabelecimento de ações intersetoriais de promoção da saúde junto à educação básica e à formação superior, para estimular mudanças na formação de profissionais de saúde em nível das graduações, residências, pós-graduação e educação técnica, tornando-as mais permeáveis às necessidades e singularidades da população. Isso contribuiria com a universalização e a equidade das ações e dos serviços de saúde ${ }^{13}$.

É importante ressaltar que, no Brasil, a questão da língua sempre foi um problema social de grande destaque, dada sua relevância na constituição do país e do sentido de brasilidade; o que vai se refletir não apenas na fala como também na escrita ${ }^{14}$. É a partir da visão de que a língua faz parte da cultura de um povo, que seria necessário levar em consideração as variações linguísticas e as produções individuais e de grupos sociais, peculiares aos usos da língua.

O discurso carrega uma bagagem ideológica e filosófica, sustentada por ideias e valores, por domínios sociais e linguísticos, pela situacionalidade e pelas condições de sua produção. Em outras palavras, o discurso configura uma dimensão sociocultural ${ }^{15}$ objetiva. Nessa perspectiva, a aproximação às problemáticas que implicam a vulnerabilidade linguística vivida por determinados segmentos sociais permitiria uma formação mais abrangente e um cuidado ampliado a essas comunidades, uma vez que a oferta de ações de saúde nesse âmbito não parece abundante.

As considerações sobre variações linguísticas, preconceitos linguísticos e algumas das relações que estabelecem com a área da saúde - brevemente apresentadas aqui - fornecem elementos para justificar a necessidade de sistematizar a reflexão sobre os impactos das variações linguísticas trazidos aos serviços de saúde, buscando 
compreender melhor as possíveis implicações do campo da saúde com o fenômeno do preconceito linguístico e seus desdobramentos no processo de saúde/doença.

O presente artigo tem como objetivo, justamente, analisar repercussões de variações linguísticas de um grupo de sujeitos constituído por jovens e adultos, buscando estabelecer indicações à reflexão sobre essa problemática no campo da saúde, especialmente no âmbito da promoção da saúde.

\section{MÉTODO}

O estudo tem natureza descritiva e caracteriza-se, em seu desenho, como um estudo de caso. Segundo Triviños ${ }^{16}$, o estudo de caso busca compreender a questão sob estudo de maneira abrangente, analisando suas especificidades e correlações com contextos sociais e políticos mais amplos. O estudo de caso produz declarações teórico-metodológicas sem, no entanto, fazer generalizações sobre seus achados de pesquisa. Nesse sentido, a contribuição do estudo de caso é delimitar situações e tendências à luz de contextos singulares, contribuindo na discussão e no equacionamento de problemas gerais ${ }^{17}$.

Para coleta dos dados foi utilizada a metodologia do grupo de discussão (GD). O GD é uma prática grupal de pesquisa qualitativa, que consiste em promover e se colocar à escuta do discurso grupal em um dado contexto ${ }^{18}$. A finalidade do GD é buscar a participação ativa dos sujeitos na pesquisa, dando liberdade para que se expressem e, por meio da conversação no grupo, colaborem na construção do discurso grupal sobre a problemática em questão ${ }^{18}$.

Para operacionalização da estratégia metodológica da pesquisa, os critérios éticos em pesquisa com seres humanos foram seguidos rigorosamente, conforme Resolução $\mathrm{n}^{0}$ 466/12 do Conselho Nacional de Saúde. O estudo foi aprovado por Comitê de Ética em Pesquisa e recebeu o CAAE 84982018.1.0000.5482. 


\section{PROCEDIMENTOS}

A pesquisa foi realizada com sujeitos inscritos em clínica-escola da Universidade do Estado da Bahia, Salvador, durante o segundo semestre de 2018, tinham entre 15-19 e 20-59 anos de idade, considerados pela classificação do IBGE como jovens e adultos, respectivamente ${ }^{19}$.

A definição dos participantes do GD foi realizada por meio de entrevista semi dirigida com os potenciais participantes (usuários em fila de espera da clínica-escola com queixa de alterações de fala com prejuízo à vida escolar, profissional ou em outras esferas sociais). O GD ocorreu semanalmente, em 08 encontros de uma hora e trinta minutos de duração cada um. Os encontros foram audiogravados, transcritos e textualizados, compondo o material de análise.

\section{APRESENTANDO OS PARTICIPANTES}

Dos sete participantes selecionados (número médio sugerido para realização do GD), um não iniciou os trabalhos, portanto o grupo foi composto por seis participantes com variações linguísticas, que aguardavam atendimento na clínica-escola e não possuíam patologias que justificassem as variações linguísticas apresentadas aspecto previamente avaliado por serviço médico e fonoaudiológico como critério de exclusão à participação no estudo.

Os participantes, jovens e adultos, eram estudantes e profissionais, conforme quadro a seguir:

Quadro 1 - Descrição dos participantes do grupo

\begin{tabular}{|l|l|l|l|}
\hline Participante & Idade & Gênero & Ocupação \\
\hline P1 & 18 & Feminino & Estudante ensino médio \\
\hline P2 & 25 & Masculino & Guia de turismo \\
\hline P3 & 25 & Masculino & Escrivão \\
\hline P4 & 28 & Masculino & Representante de vendas \\
\hline
\end{tabular}




\begin{tabular}{|l|l|l|l|}
\hline P5 & 21 & Masculino & Estudante universitário \\
\hline P6 & 50 & Masculino & Professor universitário \\
\hline
\end{tabular}

Fonte: Elaborado pelos autores.

\section{ESTRATÉGIAS DO GD}

Foram colocadas em discussão no GD as seguintes temáticas e questões:

- valores sociais da fala; preconceitos sociais e preconceitos linguísticos; relações entre origem social, hábitos, valores socioculturais e "lugar de fala"; percepções e histórias pessoais sobre os modos de falar e se comunicar, e seus impactos na pertença e na circulação social; como desejam falar e ser ouvidos: idealização, elaboração e conquista de legitimidade como falante; há distinção entre diferenças sociais e variações linguísticas?; procuraram atendimento com quais expectativas e questões pessoais, e o que pensavam após os encontros do GD?

Para discussão dessas temáticas utilizou-se os seguintes disparadores: notícias de jornal; textos com depoimentos de pessoas que apresentavam variações linguísticas; poemas de cordel; músicas e temas que os próprios participantes traziam e que propiciaram ao GD se tornar um espaço de intensa conversação.

\section{ANÁLISE DOS DADOS}

O material foi gravado em áudio e vídeo, relatado em diário de campo (com as percepções e interpretações sobre os acontecimentos) e submetido à análise de conteúdo, inspirada pela proposta de Bardin ${ }^{20}$, consistindo nas seguintes etapas: préanálise, que se deu por meio de leitura flutuante dos materiais coletados (audiovisual, texto, diário de campo); construção dos dados brutos (corpora) com dimensões e direções de análise; tratamento do material e estabelecimento de categorias de análise. 


\section{RESULTADOS E DISCUSSÃO}

Este estudo partiu de situação concreta, vivenciada em clínica-escola universitária: procura de jovens e adultos com queixas relacionadas aos modos de falar, sob a suspeita de que a discriminação aos seus modos de falar poderia indicar agravo de saúde; o que não se confirmou em avaliação médica e fonoaudiológica.

Em geral, as variações linguísticas dos sujeitos da pesquisa, fruto da diversidade sociocultural e linguística, são constituídas em função de origem, extração sociocultural e condição socioeconômica. No entanto, no discurso grupal dos integrantes da pesquisa, elas foram percebidas como variável significativa em processos de discriminação e exclusão em ambientes sociais diversos, com o agravante de que sua reiteração nesses ambientes fez parecer, aos referidos sujeitos, que se tratava de questão de saúde ou de limitação pessoal, chegando ao ponto de gerar episódios de ansiedades ou de depressão.

Para o grupo de discussão (GD), essa percepção acontece porquê as variações linguísticas, frequentemente, são consideradas desviantes e inferiores em relação à chamada norma prestigiada. Vale lembrar que a desqualificação social derivada da discriminação e do preconceito linguístico, uma vez naturalizada, sugere não discriminação, mas dificuldades ou desleixos individuais com a língua portuguesa.

Os resultados da pesquisa evidenciam à existência, no senso comum, de uma espécie de "patologização" das variações dos modos de falar, embora elas nada tenham de patológico. No entanto, esse tipo de preconceito e discriminação pode levar a efeitos sociais e subjetivos com potencial para afetar a saúde, além de prejudicar o exercício da cidadania e as oportunidades de inserção social e econômica - esses são, certamente, os principais incômodos relatados no GD.

Após o tratamento do material coletado no GD, as categorias analíticas que se depreende do discurso grupal são as seguintes: preconceito e bullying; comunidade de fala e exclusão social; e expectativas frente à norma prestigiada. Passamos a tratar de cada uma delas. 


\section{PRECONCEITO E BULLYING}

(...) as pessoas conseguem entender, mas ficam zombando. (PF)

(...) fico constrangido quando percebo que as pessoas estão com gozação. (PM)

(...) percebo o preconceito racial por conta da cor, o social pela questão financeira, o religioso por ser adepto de uma religião de matriz africana e o cultural pelo modo de falar. (PM)

(...) quando fui para um estado do sudeste senti preconceito, não tanto pela cor, mas sim por ser nordestino e falar "diferente". (PA)

Os participantes percebem que existem vários tipos de preconceito, que o preconceito linguístico é um deles e, muitas vezes, materializa e atualiza outros. Também referem o constrangimento diante da "gozação", do bullying, que comparece no discurso grupal como o modo mais frequente de desqualificação social sobre eles. Em outras palavras, a discriminação não é realizada pela exclusão pura e simples da atividade social, mas por uma espécie de "inclusão" excludente, aquela que subjuga o outro pela negação de sua pertença social, como se as diferenças expostas pela variedades linguística o tornasse inferior e não digno daquele ambiente e/ou grupo e social.

Estudo de Bagno 5 afirma que, de fato, existe demanda social por uma "língua correta", o que em si mesmo não constituiria um problema, antes corresponderia a uma aspiração social relativa mas, dentro de certos limites, legítima.

No entanto e a rigor, ninguém exerce a "língua correta" plena e perfeitamente, o problema consiste no fato de que basta a certos indivíduos ou grupos serem imaginados como desviantes do suposto padrão para que sejam vítimas de preconceito. Os participantes do GD, sem exceção, consideram isso um fato social inconteste. Além disso, alguns deles referem que é difícil não se convencer de que não sabem falar, de que falam errado ou que tem algum problema; o que corrobora a percepção sobre a "patologização" das variações linguísticas, a naturalização do 
preconceito e a eventual auto responsabilização pela discriminação de que se é vítima.

\section{COMUNIDADE DE FALA E EXCLUSÃO SOCIAL}

(...) quando passo muito tempo no interior eu assimilo muitos "vícios" de linguagem e, às vezes, falo /fio/, /muié/ e, quando percebo, corrijo. (PA)

(...) a depender do lugar que você está, você vai adaptando seu modo de falar, seu linguajar. Aqui no grupo discutimos que é normal, que é bom saber circular por vários jeitos de falar, que precisamos aprender melhor isso. (PA)

(...) a maneira como falo me atrapalha nas interações sociais e fico incomodado, por isso quero me corrigir. (PM)

As conversas no GD mostram que os participantes sabem muito bem que cada grupo ou comunidade tem maneiras próprias de falar a depender da origem, da formação cultural e da posição social e econômica que ocupam. Sabem, portanto, que a língua implica questões de poder, que se refletem em valores e hierarquias sociais ${ }^{5}$, ainda mais em um país tão desigual como o Brasil.

Santana e Neves ${ }^{21}$ dizem que as diferenças na fala precisam ser valorizadas e não discriminadas se se quiser uma sociedade democrática e, por isso, capaz de combater suas desigualdades. Além disso, os autores afirmam que, independentemente de suas variações, a língua continuará exercendo seu papel na sociedade, o que não tornará esta ou aquela variedade melhor ou pior que outras.

Os participantes do GD também relatam que as variedades linguísticas socialmente desprestigiadas, geralmente, são atribuídas às pessoas do interior ou das periferias, com baixa escolaridade e/ou baixo poder aquisitivo, e que essas variedades são vistas como "erros" passíveis de correção. O caráter urbano da norma linguística prestigiada não passou desapercebida no GD. De fato, são principalmente as capitais e grandes cidades que protagonizam as disputas econômicas, políticas e jurídico-normativas, 
daí acontecer o mesmo com a língua, uma vez que ela explicita e materializa aqueles jogos de poder.

Nessa direção, Bortoni-Ricardo ${ }^{22}$ refere que a atribuição de prestígio a somente uma variedade linguística "decorre de fatores de ordem social, política e econômica", e afirma que,

(...) no Brasil, são socialmente estigmatizados os vernáculos e as variedades populares da língua urbana. Nunca é supérfluo reafirmar, porém, que do ponto de vista linguístico, essas variedades não são estruturalmente inferiores à norma-padrão. O conceito de "erro gramatical" é tão-somente uma questão de diferença entre dois dialetos.

\section{EXPECTATIVAS FRENTE À NORMA SOCIALMENTE PRESTIGIADA}

\section{(...) pretendo falar no padrão que a sociedade acha melhor. (PM)}

Os participantes almejam falar de acordo com a norma socialmente prestigiada, mesmo percebendo - em vários momentos das discussões no GD - que ela funciona, com frequência, como instrumento de poder que os oprime; e o faz menos por questões linguísticas estritas e mais pelas engrenagens de poder e de desigualdade social das quais a norma prestigiada é representante. Ainda assim, imaginam que corresponder à expectativa de uso da norma linguística privilegiada diminuiria o sofrimento experimentado pela discriminação e pelo sentimento de limitação ou distúrbio individual.

Em parte, talvez tenham razão, mas por outro lado, essa expectativa parece apontar para inculcação acrítica de valores sociais que reiteram a discriminação de que são vítimas, não por razões linguísticas e sim, fundamentalmente, por questões de classe, de gênero e de raça. Isso não muda o fato de que o sentimento de inferioridade linguística é altamente pernicioso, pois colabora, entre outras coisas, com o silenciamento do sujeito, quando não com seu adoecimento, por não se sentir capaz de dizer sua língua e de compreender sua condição social para poder transformá-la ${ }^{23}$. 
Segundo Bagno ${ }^{24}$, o direito constitucional que é dado para todos aprenderem a norma prestigiada deveria ser o mesmo para o ensino das variações do português brasileiro. Em momento algum os falantes de variações não prestigiadas da língua deveriam se sentir linguisticamente inferiores, nem superiores à outras variações, pois "diferença não é deficiência nem inferioridade". Dependendo de com quem se fala e em que ambiente se fala, é necessário mudar o jeito de falar para ser acolhido, lembrou um dos participantes do GD (em epígrafe). De certa forma, é isso mesmo que explicitam e ao que convocam os vários gêneros discursivos e textuais: variar os modos de falar e de escrever para dar conta das exigências de contextos, situações e audiências diferentes.

\section{CONCLUSÃO}

A estratégia do Grupo de Discussão cumpriu a finalidade de produzir um discurso coletivo pelos participantes; discurso sobre o preconceito, a discriminação linguística e seus impactos na saúde. As declarações teóricas que dele podem ser extraídas vão ao encontro das premissas teóricas do estudo, no sentido de que o preconceito linguístico, como valor e conduta social, produz vulnerabilidade também no âmbito da saúde, com potencial para adoecer os indivíduos discriminados.

Além disso, é o próprio modo de falar - representativo da diversidade e da pluralidade sociocultural - que, às vezes, comparece na condição de queixa aos serviços de saúde, como se a vulneração operada pelo preconceito e pela discriminação social fosse causada, necessariamente, por problema individual de saúde. Dois destinos diferentes, mas igualmente nocivos: de um lado, possíveis alterações de saúde advindas de efeitos do preconceito e da discriminação; de outro lado, interiorização e culpabilização em face do preconceito, uma vez que a introjeção de preconceitos contra os próprios modos de falar pode levar a uma contra-identificação de parte dos brasileiros com a língua que efetivamente falam ${ }^{12}$.

Se é assim, a pergunta que dá título ao artigo só pode ter uma resposta: sim, os impactos na saúde, causados por preconceito e discriminação linguística, configuram problemáticas a serem considerados na promoção da saúde. Um dos caminhos para 
equacionar e enfrentar essa problemática seria problematizar tendências de formação e de atuação em saúde que, ao reproduzirem perspectivas "patologizantes", ajudam a naturalizar preconceitos e discriminações, reproduzindo desigualdades sociais que deveríamos ajudar a combater.

Significa dizer que não seria o caso de, simplesmente, recusar tratamento (por ausência de agravos de saúde definidos) aos sujeitos discriminados por seus modos de falar. Ao contrário, a questão parece ser acolhê-los e desenvolver conhecimentos e métodos para auxiliar na demarcação social do preconceito linguístico e dos modos pelos quais ele afeta a saúde física e psíquica dos sujeitos que procuram os serviços de saúde com esse tipo de queixa. Se a questão é pertinente, o desafio é produzir resposta e encaminhamento para ela nas políticas de cuidado, especialmente na promoção da saúde.

\section{REFERÊNCIAS}

1. Ayres JRCM, Calazans GJ , Saletti Filho, HC, Franca Junior, I. Risco, vulnerabilidade e práticas de prevenção e promoção da saúde. São Paulo: HUCITEC/ FIOCRUZ; 2009.

2. Mariani B. Entre a evidência e o absurdo: sobre o preconceito linguístico. Cad Letras UFSM 2008;:18(2):19-34.

3. Mezan R. Tempo de muda: ensaios de psicanálise. São Paulo: Cia das Letras; 1998.

4. Crochík JL. Preconceito: indivíduo e cultura. $3^{\underline{a}}$ ed. São Paulo: Casa do Psicólogo; 2006.

5. Bagno M. Nada na língua é por acaso: Ciência e senso comum na educação em língua materna. Revista Presença Pedagógica [periódico na internet]. 2006. [Acessado em 06 abril 2017]. Disponível em: http://relin.letras.ufmg.br/shlee/Bagno_2006.pdf.

6. Scarpa EM. O Jogo, a Construção, e o Erro: considerações sobre o desenvolvimento da linguagem na criança pré-escolar. São Paulo: FDE; 1991. [Acessado em: 26 set. 2016] Disponível em: <http://www.crmariocovas.sp.gov.br/pdf/ideias_10_p054-064_c.pdf>. 
7. Scoparo TRMT, Miqueletti EA. Variação linguística: língua portuguesa e o preconceito na mídia. [Acessado em 18 ago. 2015] Disponível em: http://www.baraodemaua.br/comunicacao/publicacoes/vocabulo/pdf/tania_e_e liane_volumeVI.pdf.

8. Viana MA, Lucena LVO, Vogeley ACE. A influência da fala na produção escrita

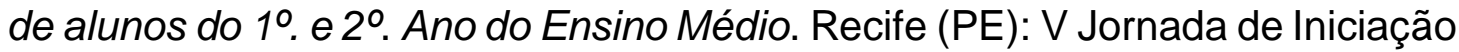
Científica; 2003.

9. Coutinho IL. Gramática histórica: Linguística e Filologia. Rio de Janeiro: Ao livro técnico; 1976.

10. Bagno M. A língua de Eulália: novela sociolingüística. São Paulo: Contexto; 2004.

11. Vogeley ACE. Variações linguísticas $X$ desvios fonológicos [dissertação]. Recife: Universidade Católica de Pernambuco; 2006.

12. Bagno M. Nada na língua é por acaso: Por uma pedagogia da variação linguística. São Paulo: Parábola Editorial; 2007.

13. Ceccim RB. Educação Permanente em Saúde: desafio ambicioso e necessário. Interface - Comunic, Saúde set2004/fev.2005; 9(16):161-77.

14. Silva MR. Alterações de fala em escolares: ocorrência, identificação e condutas adotadas [dissertação]. Campinas: Universidade Estadual de Campinas; 2008.

15. Vogeley ACE, Colares V. As variações linguísticas e a terapia fonoaudiológica: o discurso escrito em uma dimensão sociocultural. Rev Symposium 2005; 9(1):36-45.

16. Triviños ANS. Introdução à pesquisa em Ciências Sociais. São Paulo: Atlas; 1990.

17. Deslandes SF, Gomes R. "A pesquisa qualitativa em serviços de saúde: notas teóricas." In: Bosi MLM, Mercado FJ, organizadores. Pesquisa qualitativa de serviços de saúde. Petrópolis: Editora Vozes; 2004. p. 99-120.

18. Godoi CK. Grupo de discussão como prática de pesquisa em estudos organizacionais. Revista de Administração de Empresas, FGV/EAESP 2015; 55(6):632-44 .

19. Instituto Brasileiro de Geografia e Estatística - IBGE. População. Projeção da população do Brasil e das Unidades da Federação. [Acessado em 22 
ago.2019].

em:<http://www.ibge.gov.br/apps/populacao/projecao/index.html>.

20. Bardin L. Análise de conteúdo. 3를 ed. Lisboa: 70; 2004.

21. Santana J, Neves M. As Variações Linguísticas e suas Implicações na Prática Docente. Millenium 2015; 48:75-93.

22. Bortoni-Ricardo SM. Nós cheguemu na escola, e agora?: Sociolinguística e educação. São Paulo: Parábola Editora; 2005.

23. Possenti S. Por que (não) ensinar gramática na escola. São Paulo: Mercado de Letras; 1996.

24. Bagno M. Preconceito Linguístico: o que é, como se faz? São Paulo: Loyola; 2008.

Enviado: Março, 2020.

Aprovado: Março, 2020. 